\title{
ANALYTICAL PROVISION FOR MANAGING INNOVATION ACTIVITIES WITHIN THE COMPANY CONSIDERING THE INTERESTS OF STAKEHOLDERS
}

\author{
Oksana V. Portna \\ V.N. Karazin Kharkiv National University \\ Myronosytska St, 61002 Kharkiv, Ukraine, portna@karazin.ua \\ (1) https://orcid.org/0000-0002-8803-4605 \\ Natalia Yu. lershova \\ National Technical University "Kharkiv Polytechnical Institute" \\ Kirpichov St, 61000. Kharkiv, Ukraine, iershova@kpi.kharkov.ua \\ (D) https://orcid.org/0000-0003-3544-3816
}

Dina A. Tereshchenko

Kharkiv National University of Civil Engineering and Architecture

57/4 Nesterova St., 61031, Kharkiv, Ukraine, tereshchenko.dina@kstuca.kharkov.ua

(D) https://orcid.org/0000-0003-0633-0097

\author{
Tetyana Yu. Chaika \\ National Technical University "Kharkiv Polytechnical Institute" \\ Kirpichov St, 61000, Kharkiv, Ukraine, chayka@kpi.kharkov.ua \\ (D) https://orcid.org/0000-0002-7622-3193
}

George Dubynskyi

Embassy of Ukraine to the USA

3350 M Street, NW Washington DC, 20007, USA, georgii.dubynskyi@mfa.gov.ua

(D) https://orcid.org/0000-0002-7860-2437

\begin{abstract}
The article covers the problem of analytical provision for managing innovation activities within a company, taking into account the interests of stakeholders - this is connected with the possibility of ensuring the competitiveness, assessment of innovation activities and choice of innovation strategy. The purpose of the study is to identify the conditions and trends of innovation activities within companies as well as to develop a methodological approach to the evaluation of their innovation activities on the basis of accounting and analytical data considering the interests of stakeholders. The study of the current state and general trends of innovation activities at enterprises was conducted in a logical sequence as follows: 1) the number of innovatively active enterprises, 2) the share of industrial enterprises among the innovatively active enterprises, 3) the estimation of the amount of financing and the level of expenditures on innovations and 4) strategic priority directions of innovation activities that allowed to identify and analyze barriers to the development of an effective innovation policy. This provided an opportunity to develop the structure of analytical provision for the system of managing innovation activities within a company as a logical chain of strategic results for achieving economic success. However, a number of limitations and risks were identified. The assessment of the impact of innovation on the economic, environmental and social efficiency of a manufacturing production process is argued to be based on systematic and structured accounting and analytical information and reflected in non-financial reporting (in particular, the G4 Sustainability Reporting). In view of this, we consider it advisable to supplement the sustainability reporting with the indicators that characterize the effectiveness of innovation management. The results of the study are relevant and useful for large and medium-sized enterprises in the context of ensuring the implementation of an innovation model of development as well as for conducting applied research in the field of business strategies to ensure sustainable company development.
\end{abstract}

\section{Keywords}

innovation; activities; management; stakeholders; analytical provision. 


\section{Introduction}

Increasing the role of scientific and technological progress and knowledge, informatization, convergence of national economies, increased competition in markets as well as intensification of social and cultural ties are important trends in the development of society worldwide. An innovative model of developing the economy is widely recognized and in particular has been reflected in the European Union's Europe 2020 strategy [1], which is based on flagship initiatives to deliver rational, sustainable and inclusive growth. Fundamental transformations in business and manufacturing processes, service delivery, organizational methods and other non-technological innovations are equally important. The innovation-orientated companies are certain to enter new markets, change the model of doing business, apply original methods to reduce expenses, find new opportunities and resources, and as experts say [2], apply new products and tools in the market of innovative technologies such as electronic money, cryptocurrency, etc. The changes taking place cause the development of goal-setting systems, tasks of current and strategic development, their detailing, integration and transformation in different fields and directions of individual activities.

The international scientific community is currently focused on studying a wide range of aspects of company innovation activities and new ways of enhancing innovation management efficiency, implementing innovations in different areas of company functioning and applying different approaches, methods and indicators to the analysis of innovation activities. We agree [3] that innovation has a strong positive impact on social development, and innovation increases the quality of life.

According to experts, new technologies have already influenced almost every aspect of human life. Today, in the face of significant changes, innovation is becoming one of key elements of stability and considered one of the most important requirements for companies. Strong competition together with the need to compete with new market players requires the development of new skills in managers and employees. Thus, it becomes important to study the extent to which innovations may affect the company's performance that leads to the business's stable position on the market, to evaluate them in terms of their potential in the process of creating competitive advantage and to analyse the relationship between the level of innovation efficacy and market efficiency. Research studies regarding innovation are mostly focused on developed countries, and very little is known about transition economies [4].

Empirical data and available research papers show that innovation efficiency is greatly enhanced through close cooperation between the entities involved in innovation activities [5]. According to Pelse et al. [6], bioeconomic enterprises in Latvia have highly valued the cooperation with research institutes in the development of innovations. This cooperation is embodied in the formation of the global innovation system that is currently characterized by certain trends, among which; the functioning of the world technology market occupies the leading position. Innovation activities can be enhanced through stakeholder engagement, which is aligned with strategic goals and supported by adequate incentives and management mechanisms. This includes, among others, CRM (customer relationship management), GR (government relations), and PR (public relations). At the same time, such relationships (communications) with stakeholders are considered as part of the company's intangible assets [7]. Moreover, collaboration with stakeholders promotes structural changes in the economy and society and is able to influence the entire value chain, from suppliers to end users. When studying the issue of conflicts of interest between stakeholders with respect to sustainable territorial development [8], key components of a modern industrial strategy have been identified based on stakeholder collaboration (Fig. 1). 


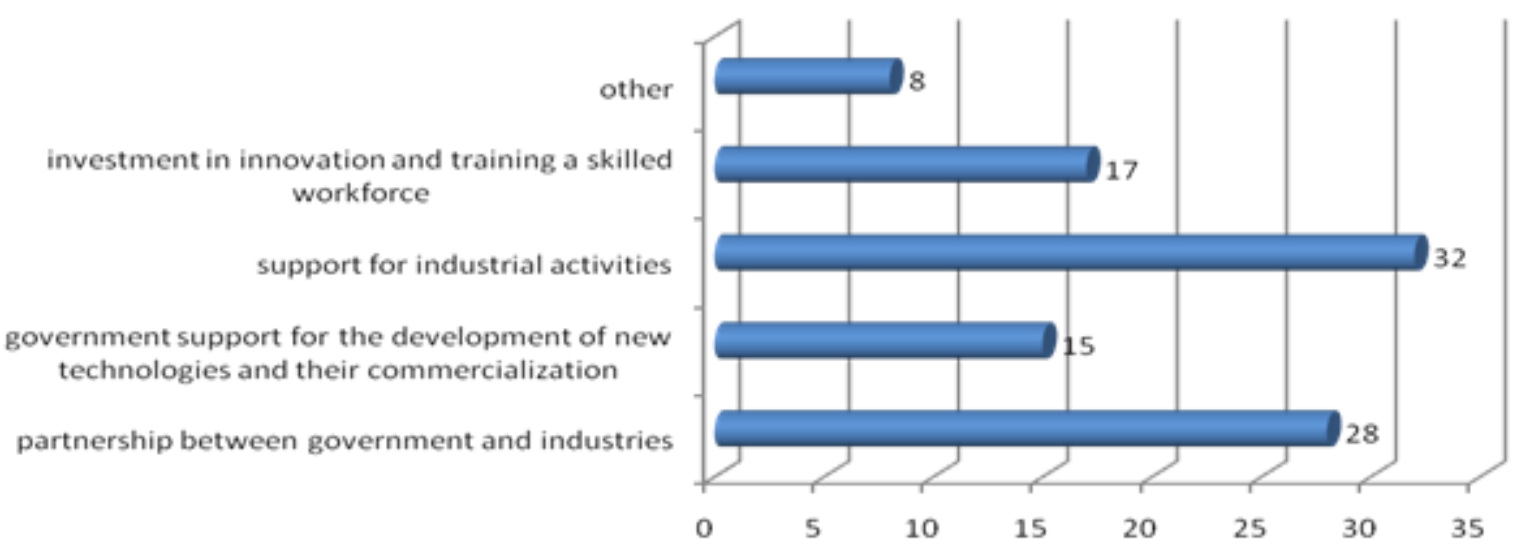

Fig. 1. Key components of a modern industrial strategy identified through stakeholder collaboration. Source: Source: Own research

Of the respondents, $28 \%$ identified the partnership between government and industries as an institutional mechanism for innovative change, $15 \%$ noted government support for the development of new technologies and their commercialization in accordance with the strategy, 32\% identified support for industrial activities in enhancing the economy of the country, and $17 \%$ emphasized investment in training a skilled workforce of the future for a term beyond 5-10 years including medium and long-term goal setting based on the analysis of identified challenges for the future of development; defining strategies by type of activity; creation and support of development institutes by priority activities (32\% of respondents).

Transition to an innovative type of development offers great prospects but also creates significant risks to the stability and balance of the development itself at macro and microeconomic levels. Risks can have a negative impact on the design of innovation projects including financial, marketing, intellectual, technical, information and institutional projects. Therefore, experts are invited to apply methods of reducing investment risks when implementing projects at enterprises by clearly identifying sources of investment risks and their possible impact; timely observation of the macro and microenvironment during the implementation of innovation projects; clearly controlling the risk management process; and through available resources needed to ensure fast actions and a sufficient timeframe for project implementation $[9,10]$.

Addressing conflicts of interest between stakeholders in sustainable territorial development has made it possible to explore and isolate barriers to building an effective innovation policy at the macro-level. The most significant are identified as follows: low-developed innovative infrastructure and weak development institutions, economic and political instability, migratory aspirations among highly educated youth and scientists, weak venture funds and underdeveloped system of regulating their activities as well as taxation (Fig. 2).

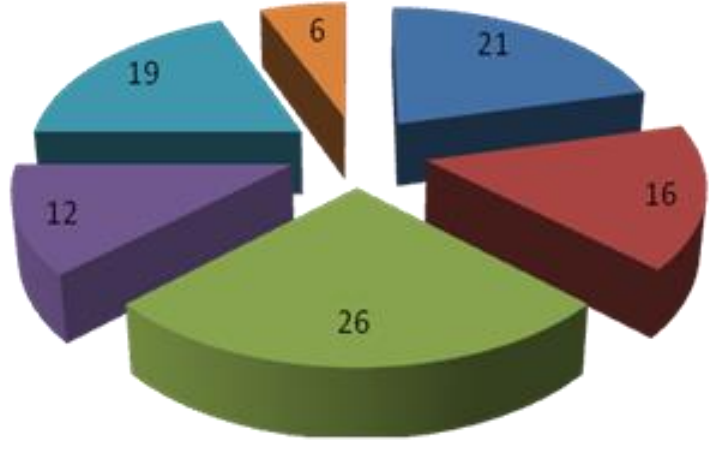

- economic and political instability

migratory aspirations among highly educated youth and scientists

- low-developed innovative infrastructure

- underdeveloped financial system under the assistance of government

weak venture funds and underdeveloped system of regulating their activities

w other

Fig. 2. Barriers to building an effective innovation policy. Source: Source: Own research 
According to E. Witjara, et al. [11], innovation processes in industry are predominantly extensive in their nature and new products are being mastered mainly through the use of scientific and technical assets of previous years. This type of innovation development is certain to have narrow limits and will not allow enterprises to maintain long-term competitiveness. Thus, the elimination of barriers to a modern innovation policy also comes down to the active use of strategic innovation. The researchers' findings [11] confirm the importance of strategic innovation for shifting to a new level of technological structure. The concept of strategic innovation lies at the intersection of strategic and innovation management and defines strategic innovation as a preventative innovation aimed at creating new competitive advantages for companies to ensure their competitiveness and increase business value. When studying the role of strategic innovation in digital companies, Perevozova et al. [12] emphasize the integrative, multidisciplinary, and "holistic" nature of any strategic innovation.

The main goals of the innovation management system are those of the entity itself. The development of an innovation management system must be geared towards achieving these goals. The effectiveness of the company's innovative growth management processes is characterized by a number of indicators that reflect the efficiency of implementing innovative solutions. Researchers Freeman and Dmytriyev [13] determine the following indicators to evaluate the actual state of enterprise innovation management systems as follows: level of material and financial resources, social and psychological climate, leadership style, human potential, system of evaluation of work results and incentives, flexibility and mobility, communication processes and information support of innovation activities. According to the scientists, the indicators differ in their significance and unevenly affect the innovative management system activities [13]. At the same time, a number of scientists dealing with micro-level innovation management emphasize the need for monitoring the state of the system and achieving its goals, preparing operational data for senior executives on the current state and development of the system; accumulating and synthesizing information on the factors of the system development; organizing information exchange among employees of the system, creating options for the strategy of managing the innovation activity development considering the existing goals and objectives; evaluating possible consequences that result from implementation of regulatory decisions related to the management system development; and controlling and analysing the reasons for not having implemented these decisions [13].

The researchers Khaustova et al. [14] believe that the processes of managing innovation activities regard social innovations and their evaluation. Indeed, innovations should cover both the development of socio-economic development strategies in general and the development of strategies for enhancing the competitiveness of human capital in particular. The role of social innovation must be diagnosed both as a whole and within individual activities. In terms of economic activity, this regards the development and implementation of economic management methods, accompanied by the needs of prognostication, synthesis of strategies, strategic and current plans, financing needs, remuneration, pricing, analysis and evaluation of the state of the environment, performance evaluation, monitoring of economic processes by directing them towards visionary and innovative development, application of new knowledge, experience and developed competencies.

\section{Methods}

The authors used general-scientific and special methods of cognition. An analysis of the current state and general trends in innovation activities at Ukrainian enterprises, the evaluation of the amounts financed and spent on innovation was carried out with the help of the comparative statistical analysis, which made it possible to identify barriers to the development of an effective innovation policy. The next step was to use logical and systematic approaches to build a system of analytical provision for the company's innovation management as well as to take into account interests of stakeholders and their engagement. This plays an important role in all types of innovation processes not only in business model innovation. The methodological approach to assessing the company's innovation activity was developed using a SWOT analysis and a SPACE-matrix, which makes it possible to determine and evaluate the indicators of innovation activities as well as to justify the choice of an innovation development strategy. The next step was to evaluate the effectiveness of innovation management within the company on the basis of the coefficient method. The further use of the graphical method was aimed at illustrating the results of the study. The research structure was built, and the conclusions were made with the help of the structural-logical method and the method of scientific generalization. 


\section{Results and discussion}

1. Innovation activities as a key factor in the development of companies: analytical aspect

The main factor that determines the development of the national economy is innovation based on the use of new ideas, scientific knowledge, technologies and products in various sectors of industry and management. The analysis of the state of innovation activities at Ukrainian enterprises is defined as one that does not meet the needs of innovative development. According to the Global Innovation Index 2018 ranking, the top innovative economies are represented by Switzerland (number-one spot for 5 years), Netherlands, Sweden, United Kingdom and Singapore. The top 5 middle-income countries are represented by China, India, the Russian Federation, Brazil and Argentina. In 2018, Ukraine ranked $43^{\text {rd }}$, meaning it was among the countries with lower-than-average per capita income [15]. According to the European Innovation Scoreboard 2018, Sweden tops the list of innovative countries. The group of leaders also includes Denmark, Finland, Germany and the Netherlands. With respect to the European level, Ukraine's position has lowered, and our country is ranked as a European outsider for innovation (together with Romania and Bulgaria) [16]. The trajectory of Ukraine's development differs significantly from the general trends in modern transformations, which are characteristic of the highly developed economies where innovations are becoming dominant. The steady reduction in the actual amount of financing of the scientific and technical complex and the lack of effective scientific and technical policies are not grounds to conclude that there is a real basis for the transition to an innovative model of development. During 20102018, the number of innovatively active industrial enterprises in Ukraine decreased by 685 units. However, the percentage of the total number of industrial enterprises increased by $2.6 \%$. According to the studies carried out in 2011-2018, the most innovative enterprises comprised small and medium-sized companies, the share of which as the total number of innovative enterprises was about $70 \%$ - this was due to the structure of the survey samples rather than the greater propensity of small businesses to innovate. During 2016-2018, the share of enterprises engaged in innovation activities by recommended types of economic activity was $18.4 \%$ including technological innovation - $11.8 \%$ (product [5.7\%] and process [10.3\%] innovations), non-technological innovation - 13.4\% (organizational [8.7\%] and marketing [10.2\%] innovations); $72.8 \%$ of innovative enterprises were engaged in organizational (47.4\%) and/or marketing (55.4\%) innovations [17]. One of the indicators of company's innovation activities is innovation expenditure. Thus, in 2018, the cost of innovation at industrial enterprises increased by $51.39 \%$ compared to 2011 and by $33.59 \%$ compared to 2017 (Fig. 3).

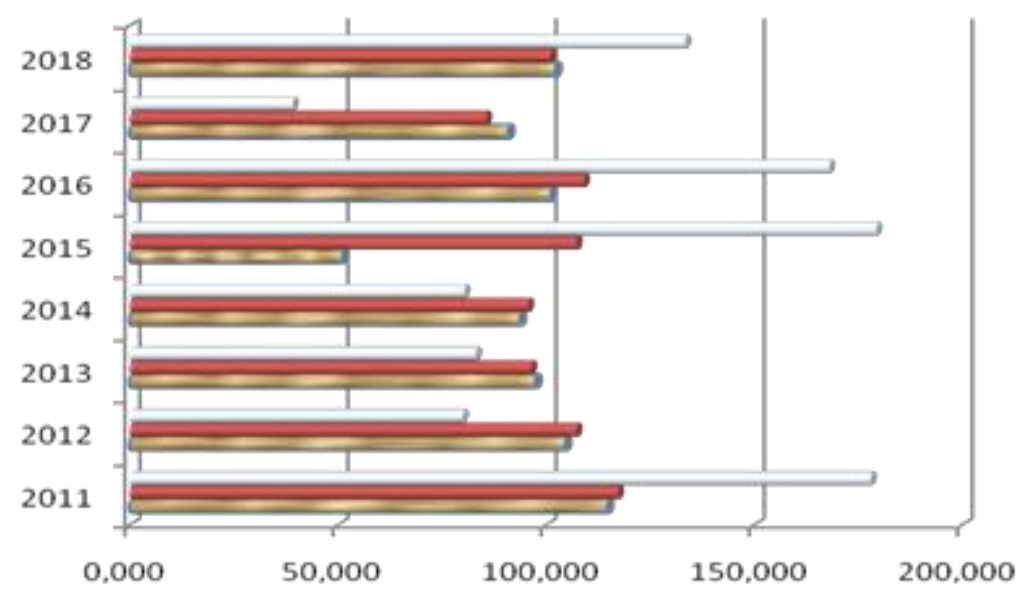

E Innovation expenditure, mI. UAH

= \% of the total number of industrial enterprises

Number of innovatively active industrial enterprises

Fig. 3. Comparative analysis of innovation expenditures at Ukrainian enterprises. Source: [17]

The total amount of expenditures classified by the directions of innovative activities at Ukrainian enterprises comprised 13,813.7 million UAH (2016), 9,117.5 million UAH (2017) and 12,180.1 million UAH in 2018. Moreover, the change rate for internal researches comprised $5.845 \%$ in 2017 and $39.401 \%$ in 2018 compared to previous years, respectively. The change rate for external researches of Ukrainian industrial enterprises constituted $11.246 \%$ in 2017 and $119.96 \%$ in 2018 compared to previous years, respectively. The pace of change in purchasing machinery, equipment and software and acquiring other external experiences slowed down in 2017; however, in 2018, the innovation expenditure in these fields significantly increased. Thus, Ukrainian enterprises were unable to reach the level of innovation activity observed at the beginning of the 21st century - this confirms the urgency of the problem of enhancing innovation activities by domestic enterprises. 
A significant factor that influences the implementation of innovation is the availability of financial security. Thus, the strategic priority innovation areas are defined as follows: 1.) Development of new energy transportation technologies, introduction of energy efficient, resource-saving technologies, and development of alternative energy sources. 2.) Acquisition of new technology for high-tech development of transport system, rocket and space industry, aviation and shipbuilding, armament and military equipment. 3.) Development of new technologies of production, processing and combining new materials, development of nanomaterial and nanotechnology industries. 4.) Technological renewal and development of agro-industrial complex. 5.) Introduction of new technology and equipment for high quality health care, treatment, and pharmaceuticals. 6.) Widespread application of cleaner production technologies and environmental protection. 7.) Development of modern information, communication technologies and robotics.

The analysis shows that in 2018, despite a slight increase in total amount, funding for all strategic priorities has increased compared to 2017. The shares of individual areas (2, 3, and 7) also increased in 2017 and 2018 in respect to the total amount of financing. The largest financing amount $(153,444.23$ thousand UAH or $52.6 \%)$ is directed to the strategic Priority 4 (Fig. 4), the smallest one (5,356.06 thousand UAH or $1.8 \%)-$ to Priority 5 [17].

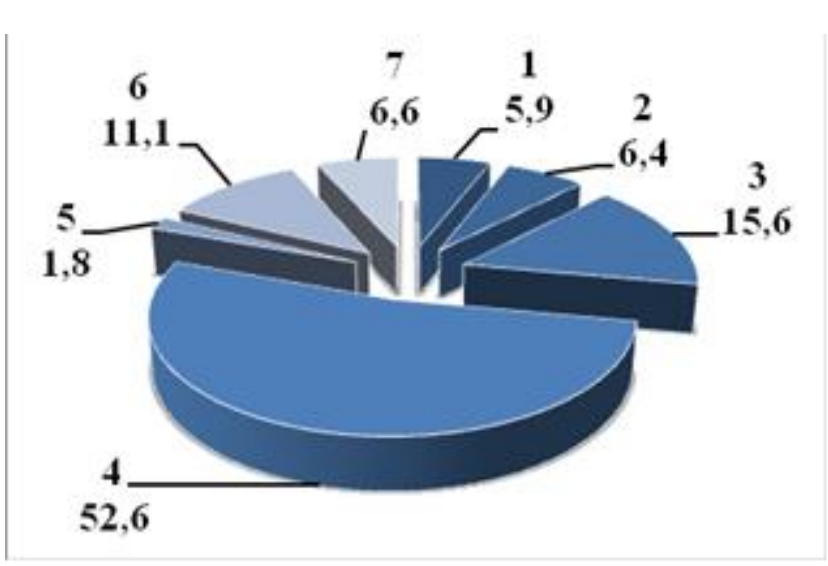

2018

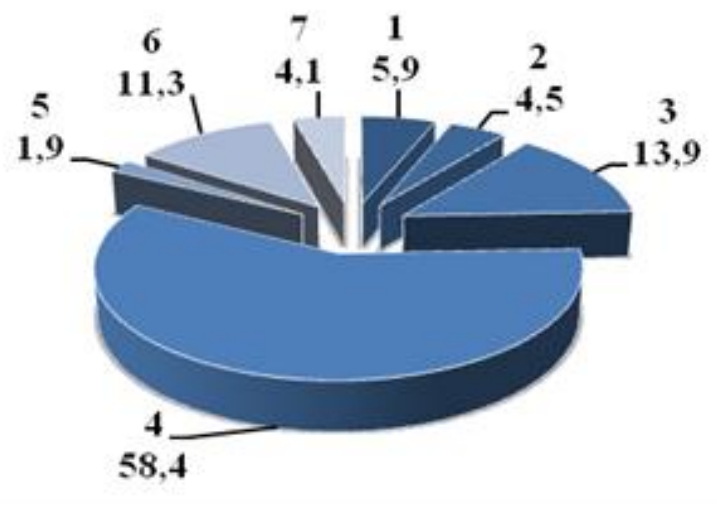

2017

Fig. 4. Assessment of financial support by strategic priority areas of innovation activities at Ukrainian enterprises. Source: Source: Own research

Kvitka and Kramarenko [18] identified the increasing role of small and medium-sized enterprises (SMEs) in many countries of the world. The researchers point out that the engines of scientific and technological progress are individual entrepreneurs, inventors and innovators who are witness to the complex and rigid structure of large organizations hampering their growth. Small and medium-sized enterprises are becoming the most convenient form of implementing and promoting innovation. Ziyadan et al. [19] concluded that special attention is paid to the development of organizational and managerial innovations, which, as a rule, lead to resultant effects. The indicators of innovative activities are widely used to evaluate the innovative activity within the company and its innovative competitiveness. At the same time, the need for product innovation management is emphasized by Vishnich, Wingarten and Neely [20]. The authors investigated the methods of managing innovation in business service models and evaluated their impact on productivity [20].

2. Analytical provision for innovation activities within the company

The peculiarity of this study is that accounting and analytical support for managing the innovation activity at an enterprise is a complex system in which the input information is registered, processed using analytical methods and stored for management purposes to evaluate the effectiveness of innovation activities and make efficient management decisions. A study by Bondar et al. [21] indicates the feasibility of presenting analytical data as a logical chain of strategic results. Fig. 5 displays the basic blocks in the system of accounting and analytical support for managing innovative activities within the company. 


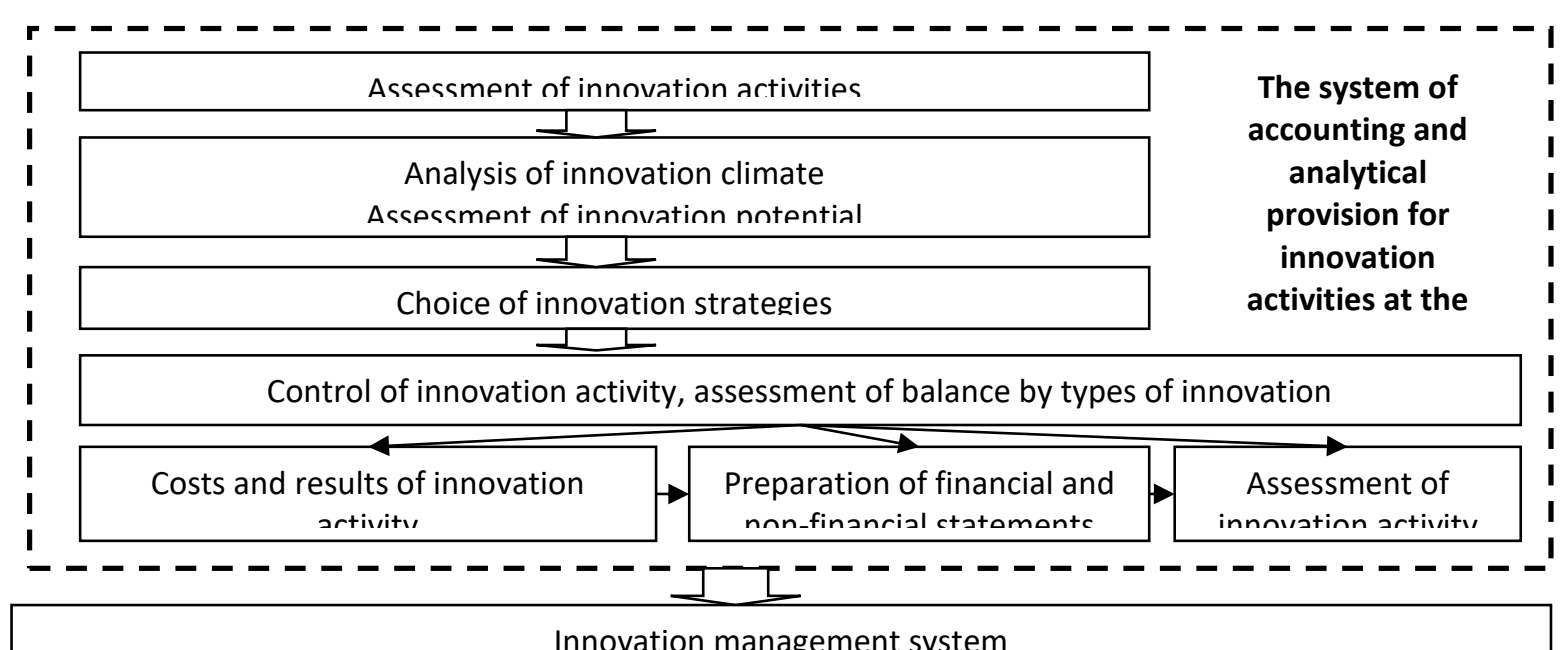

Innovation management svstem

Stakeholders

Fig. 5. Analytical provision for innovation activities within the company. Source: Source: Own research

Mutanov, Ziyadin, and Shaikh investigated the problem of improving the efficiency of eco-innovative projects aimed at ensuring sustainable development [22]. The researchers suggest evaluating innovativeness, competitiveness and environmental efficiency on the basis of graphical models.

Analytical support for innovation management should take into account stakeholder engagement, which plays an important role in all types of innovation processes, not only in business model innovation [23]. The stakeholder engagement system includes identification of stakeholders, gathering information on key stakeholders, identifying their interests, degree of influence on innovation activities within the company, and areas of influence; analysis of opportunities and prospects for stakeholder engagement; monitoring and evaluating the effectiveness of stakeholder engagement. For identification, it is suggested to make a separate entrance evaluation card for each stakeholder. An initially created stakeholder map is the primary planning document and will continue to change as the project progresses. The stakeholder engagement system is effective when the company goals are understood and accepted by all the stakeholders, i. e. nothing causes counteraction and all actions of the stakeholders are aimed at meeting the common goals. According to the authors of the present paper, the principles of effective cooperation with stakeholders to ensure the efficiency of the innovation activities within the company are significance, completeness and responsiveness. Significance requires knowledge of what is truly important for stakeholders; completeness is based on understanding the needs of stakeholders, ability to influence their expectations and perception of results; and responsiveness requires the ability to take adequate actions on issues that are relevant to stakeholders and companies.

3. Methodical approach to evaluation of innovation activities within the company

We suggest starting an analysis of innovation activities by selecting approaches to solve the issue of evaluating the company's ability to implement innovation projects and outline promising areas of development. The basis of information for evaluating innovation activities within the company is the data retrieved from accounting reports, planning and financial documentation, research and development papers of the company, statistical reports, and expert opinions in the field of innovation. The subjects of carrying out evaluation of innovation activities are specialists in managing innovative processes in a company, i. e. business analysts. We suggest dividing the system of indicators to evaluate innovation activities in a company into two groups - indicators that characterize the innovative potential and indicators that characterize the innovative climate. Each of the indicators in these groups can be expressed qualitatively and quantitatively. To assess the innovative potential, we selected the groups of indicators that characterize the material, technical, personnel, financial, and information and communication potentials. 
According to Bondarenko et al.[24], the innovative climate includes the factors of micro- (market) and macroenvironment. Therefore, the groups of indicators that characterize the social infrastructure, technological and scientific-technical fields, economic and financial, political and legal sectors have been selected to evaluate the innovative climate. An instrument for evaluating the elements of innovative potential is a SWOT analysis. According to the latter, each element of the potential based on the nature of its impact on the company's activities is defined as $\mathrm{S}$ (strong), $\mathrm{N}$ (neutral) or W (weak) (Table 1). As a neutral evaluation, the average market value of the potential element is recommended in this case. The integral value of the innovative potential in a resource block is determined by the number of its strengths and weaknesses. When working on the contractual topic "Development of Recommendations for Improving Strategic Management Accounting and Analysis to Ensure the Economic Security of the Subject of Economic Activity in the Context of Adaptation to Market Conditions", the developers evaluated the innovative activities of the five Ukrainian machine-building enterprises. The results for Enterprise 1 are shown in Tables 1-2 and Fig. 6.

Table 1. Evaluation of the innovative potential for Enterprise 1. Source: Source: Own research

\begin{tabular}{|c|c|c|c|c|}
\hline \multirow{2}{*}{ No } & \multirow{2}{*}{ Indicators for evaluating the innovative potential by blocks } & \multicolumn{3}{|c|}{$\begin{array}{c}\text { Qualitative evaluation of the } \\
\text { position }\end{array}$} \\
\hline & & $\begin{array}{l}\text { strong } \\
\text { (S) }\end{array}$ & $\begin{array}{l}\text { neutral } \\
(\mathrm{N})\end{array}$ & $\begin{array}{l}\text { weak } \\
\text { (W) }\end{array}$ \\
\hline 1 & material and technical resources & & & \\
\hline 1.1 & equipment and tools availability & + & & \\
\hline 1.2 & supply of raw materials, fuel and energy & & + & \\
\hline 1.3 & area, communications and transportation availability & & + & \\
\hline 1.4 & $\begin{array}{l}\text { effective application of material and technical resources (material } \\
\text { intensity, capital intensity, capital efficiency, profitability of fixed } \\
\text { assets) }\end{array}$ & + & & \\
\hline 2 & manpower (staff) & & & \\
\hline 2.1 & number of staff associated with innovation & + & & \\
\hline 2.2 & $\begin{array}{l}\text { structure of the personnel engaged in innovation activities within the } \\
\text { industrial production personnel }\end{array}$ & & & + \\
\hline 2.3 & composition and qualification of management personnel & & & + \\
\hline 2.4 & list of specialists and their qualification & + & & \\
\hline 3 & financial resources & & & \\
\hline 3.1 & share of money for development & & & + \\
\hline 3.2 & own sources of funds available to finance scientific researches & & + & \\
\hline 3.3 & use of long-term sources in financing innovation activities & + & & \\
\hline 3.4 & working capital provided for the innovation activity & & + & \\
\hline 4 & information resources & & & \\
\hline 4.1 & databases accessibility & & + & \\
\hline 4.2 & patents availability & + & & \\
\hline \multirow[t]{2}{*}{4.3} & communication resources availability & & & + \\
\hline & overall score & 6 & 5 & 4 \\
\hline
\end{tabular}

The factors of the company's macro-environment (macro-climate) (Table 2) are evaluated the same way as the innovative potential with each factor of the macro-environment affecting the innovative development of the company to be evaluated as an opportunity, a risk or one with neutral influence. The integral value of the innovative climate condition is determined by the number of opportunities and risks. 
Table 2. Evaluation of the innovative climate at Enterprise 1. Source: Source: Own research

\begin{tabular}{|c|c|c|c|c|}
\hline \multirow[b]{2}{*}{ No } & \multirow[b]{2}{*}{ Indicators for evaluating the innovative climate by blocks } & \multicolumn{3}{|c|}{ Qualitative evaluation of the position } \\
\hline & & $\begin{array}{l}\text { opportunities } \\
\text { (O) }\end{array}$ & neutral $(\mathrm{N})$ & $\begin{array}{l}\text { risks } \\
(\mathrm{R})\end{array}$ \\
\hline 1 & \multicolumn{4}{|l|}{ Social } \\
\hline 1.1 & level of education & + & & \\
\hline 1.2 & level of social stability & & + & \\
\hline 1.3 & $\begin{array}{l}\text { proportion of employees involved in scientific and research } \\
\text { work }\end{array}$ & + & & \\
\hline 1.4 & new methods of managing social processes & & & + \\
\hline 2 & scientific and technical & & & \\
\hline 2.1 & quality of innovation infrastructure & + & & \\
\hline 2.2 & $\begin{array}{l}\text { advanced production technologies } \text { (developed and } \\
\text { implemented) }\end{array}$ & & + & \\
\hline 2.3 & $\begin{array}{l}\text { volume of innovative products, works, services and supplies } \\
\text { and their share in total production }\end{array}$ & + & & \\
\hline 2.4 & level of technology commercialization & & & + \\
\hline 3 & Economic & & & \\
\hline 3.1 & tax policy & & + & \\
\hline 3.2 & level of financing for the innovation activity & & & + \\
\hline 3.3 & macro-financial stability & & + & \\
\hline 3.4 & the scale of budgetary spending on science and innovation & & & + \\
\hline 4 & political and legal & & & \\
\hline 4.1 & the level of state support for high-tech industries & & + & \\
\hline 4.2 & legal acts in relation to property rights & & + & \\
\hline 4.3 & international cooperation & & & + \\
\hline & overall score & 4 & 6 & 5 \\
\hline
\end{tabular}

The evaluation of innovation activities within the company provides recommendations for defining or adjusting the innovation strategy. A four-dimensional SPACE matrix is used to determine the projected position of the company and the corresponding innovation strategy (Fig. 6) is modified according to the specifics of the tasks being fulfilled and integrated with the method of the SWOT analysis. In the SPACE matrix, the coordinates that reflect environmental factors are opportunities and risks $(\mathrm{O}, \mathrm{R})$ due to the innovative climate. The coordinates that reflect the factors of the internal environment are the strengths and weaknesses of the innovative potential $(S, W)$. The number of strengths and weaknesses of the innovative potential are reflected in the positive and negative values of the abscissa $(X)$ axis, and the number of opportunities and risks are represented on the positive and negative section of the $y$-axis $(Y)$, respectively. The specific values of the indicators plotted on each axis are joined with straight lines resulting in a quadrilateral. The polygon side, which is at maximum distance from the centre, shows the vector of company development and, thus, the most innovative strategy under the given conditions. This procedure of evaluating the innovative potential and innovative climate is carried out for each scenario. 
Opportunities (O)

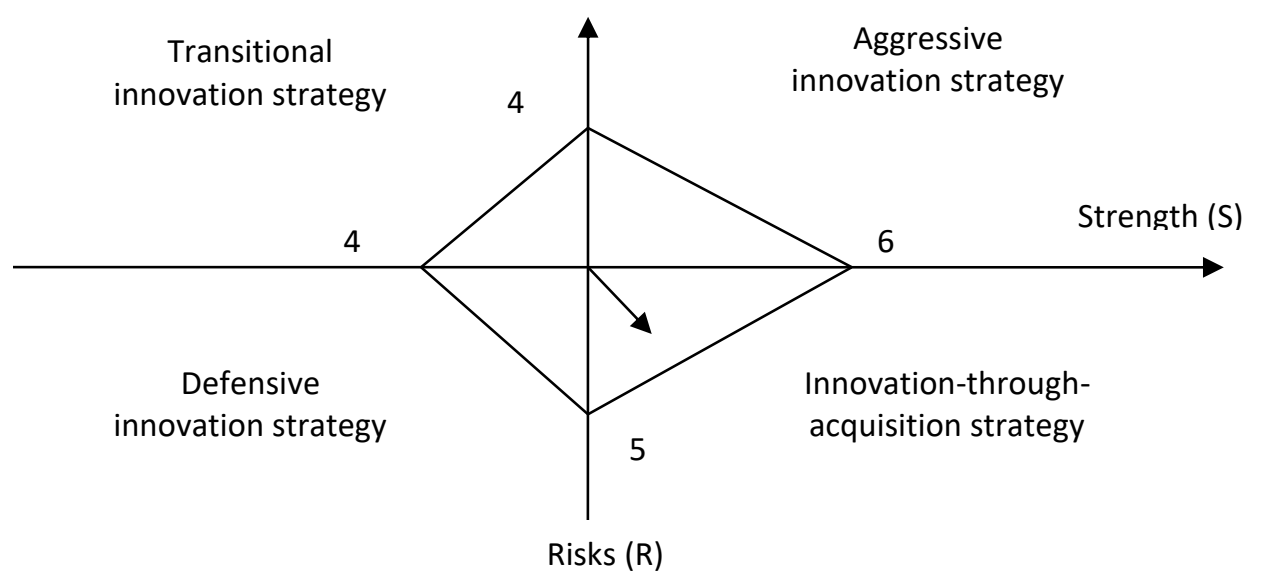

Fig. 6. SPACE matrix for defining a promising strategy. Source: Source: Own research

According to the foreseen alternative scenarios of environmental development as well as the existing innovative potential, there are four possible options for the company's position on the SPACE matrix, namely:

- position in S-O quadrant. The company has a high level of innovative potential and opportunities for innovative development driven by a favourable innovative climate. This is the best position in the matrix and the company is recommended to implement an aggressive strategy aimed at improving its competitiveness through the independent development of fundamentally new products and active work on fundamentally new innovation projects. The aggressive strategy requires high qualification and experience of the employees in innovations and a certain reserve of different types of resources. The implementation of this strategy is associated with significant capital investment and is characterized by an increased level of risk,

- position in S-R quadrant. The position identified for the company is characterized by an unfavourable innovative climate. However, there are some resources to reduce the negative impact of external threats. In order to maintain competitiveness and further innovative development of the company, it is recommended to implement an acquisition strategy focused on introducing innovative solutions. Such a strategy may not fully contribute to the achievement of the company's overall objective, but it does create the conditions for a balanced allocation of resources between conducting its own research and acquiring licenses and the know-how,

- position in $\mathrm{W}-\mathrm{O}$ quadrant. The position defined for the company is characterized by the presence of certain external opportunities for the development due to a favourable innovation climate despite a low level of innovative potential. Under these conditions, the company is recommended to use a product differentiation strategy or innovation projects to maintain their competitive position in the market. Such a strategy will allow the company to occupy its own niche and evade direct competition with giants in the market and to use external opportunities for development of innovative potential,

- position in $W-R$ quadrant. The position identified is the worst for the company, as the company does not have sufficient resources to reflect the external risks caused by the unfavourable innovation climate. In view of this situation, the company is recommended to employ a defensive strategy that minimizes risks and reveals hidden reserves for the development of innovative potential by carefully selecting promising innovation projects and paying special attention to the production and marketing sectors in the process of their implementation. The main purpose of this strategy is to select innovation projects that ensure the company to maximize profits in the short term to stabilize its position.

According to the accounting data for Enterprise 1, the company is recommended to implement an acquisition strategy focused on introducing innovative solutions.

To evaluate the effectiveness of innovation management, we suggest calculating the following indicators:

https://doi.org/10.32933/Actalnnovations.34.3 •ISSN 2300-5599 • (C) 2019 RIC Pro-Akademia - CC BY 
1. Growth rate of intangible assets (IA), GRIA:

$$
G R I A=\left(I A_{1}-\mid A_{0}\right) / I A_{0}
$$

2. Growth rate of net profit (NP), GRNP:

$$
\text { GRNP }=\left(N P_{1}-N P_{0}\right) / N P_{0}
$$

3. Growth rate of sales volume (SV), GRSV:

$$
\mathrm{GRSV}=\left(\mathrm{SV}_{1}-\mathrm{SV}_{0}\right) / \mathrm{SV}_{0}
$$

4. Sales expansion rate (S), SER:

$$
\operatorname{SER}=\left(\mathrm{S}_{1}-\mathrm{S}_{0}\right) / \mathrm{S}_{0}
$$

5. Innovation commercialization rate (C), ICR:

$$
\operatorname{ICR}=\left(\mathrm{C}_{1}-\mathrm{C}_{0}\right) / \mathrm{C}_{0}
$$

6. Eco-costs rate (Ec), ECR:

$$
E C R=\left(E c_{1}-E c_{0}\right) / E c_{0}
$$

This is of particular relevance in the context of implementing the sustainable development concept, which provides for the compilation of appropriate G4 reporting to present information about the impact caused by the company's activities on the economy, environment and society. By including the indicators used to evaluate the efficiency of managing the innovative activity in the Sustainability Report of the enterprise (namely, in the section on corporate governance quality indicators) we make it possible to ensure balance of interests of stakeholders.

Thus, the scenario of choosing an innovative strategy is refined taking into account a specific strategy and efficiency of managing the innovation activity within the company. This allows identifying promising areas of the activity and evaluating the priority of developing innovation projects.

We agree with Slinták, Briš and Jurigová [25] regarding the priority of innovative solutions that implies the implementation of such measures resulting in the achievement of the objectives of innovation activities with minimum expenses but maximum economic effect. In doing so, the results of evaluating a company's innovation performance can be used to develop a marketing strategy to become an industry leader [26]. BrodowskaSzewczuk [27] presents the determinants for the development of innovative activities within the company in terms of economic competitiveness. To evaluate the company's innovation, researchers are offered tools of competitiveness such as an analysis of the introduction of new products, product quality, and evaluation of relationships between stakeholders. According to the researchers, the internal capabilities of a company to innovate [27] are presented by an increase of productivity or production capacity, modern methods of production and service, cost reduction, improvement of work processes, innovations in management. The consequences of this approach are as follows: increased number of customers, growth in a market share, enhanced brand awareness, expanded market outreach, increased profitability of production and services, higher revenues and net income growth. Pesti et al. also emphasize the importance of the four aspects (4P) of an innovation research including Product Innovation (that is, changing a product or service offered by a company),

Process Innovation (changing the way you create and deliver services and products), and Position Innovation that changes the context of Product Innovation Paradigm implementation, which alters mental models [28]. 
Many experts offer to create a subsystem for monitoring the processes of increasing investment potential, whereby the company can track the indicators of the investment potential level through feedback channels and implement innovation projects to increase them.

The study of the theoretical and practical developments carried out by these scientists suggests that they have deepened the theoretical foundations and practical tools for analyzing innovative activities within the company. However, the analytical provision for managing the innovation activities requires improvement in order to evaluate the prospects for the company's development considering the goals of stakeholders - this issue determined the choice of the research topic.

\section{Impact}

Evaluation of innovation is an element of analytical support for general management, which affects the economy by improving the company's efficiency and sustainability. Business efficiency can also be enhanced by improving business processes. However, there are some limitations and risks that need to be identified. First, the resources owned by the company are limited; thus, they should be sufficient to finance on-going activities and implement innovation projects. Secondly, innovation is associated with a higher level of risk, and therefore innovation risks also impose limits on the scope of innovation projects. The third and the most important limitation is the need to consider and reconcile the interests of key stakeholders. All innovation projects implemented should comply with the interests of the relevant stakeholder group without running counter to the interests of other stakeholder groups. However, the approach to analytical provision for innovation management should be based on the belief that it is intended to provide opportunities and not to limit them. Therefore, the impact on the economy through the introduction of analytical support for the innovation management taking into account the interests of stakeholders has the following characteristics:

- better management of the company's innovation and reputation,

- comprehensive assessment of the external business environment including the development of markets and the identification of new strategic opportunities,

- building trust between the company and its stakeholders,

- receiving information from stakeholders that may lead to improvements in business processes,

- informing and influencing the stakeholders and the business environment to improve the decisionmaking process and facilitate the commission of acts that affect both the enterprise and society,

- $\quad$ and building the company's image as a socially responsible business unit.

It should be noted that the impact of innovation on the economic, environmental and social efficiency of production should be evaluated based on a systematic and structured accounting and analytical information and reflected in non-financial statements, in particular, the G4 Sustainability Reporting. In view of this, we consider it advisable to supplement the sustainability reporting with the indicators that characterize the effectiveness of innovation management.

\section{Conclusions}

Today, the economic growth and economic development of domestic enterprises depend on the conditions of the innovation activities, the analysis and evaluation of which defines opportunities for creating and implementing innovation and raises interest among stakeholders. The success of innovation depends on the availability of specific methods aimed at making the most objective decisions in the field of enterprise innovation policy.

The novelty of the present research comprises a methodological approach to the evaluation of innovation activity by comparing the innovative potential of the company and its innovative climate. This allows taking into account the specifics of the company's activities, choosing among various indicators as well as presenting the results in a graphic format to further define the most promising and realistic strategy.

Based on official statistics, generalized conclusions have been made about the number of innovation products developed and sold as well as the amount of financing for innovation activities, types of innovation, the amount of costs spent on innovation, etc. However, in the context of innovative development these indicators do not allow making objective conclusions about the prospects for the development of innovation activities at an enterprise. 
The development of a methodology for the analysis of an innovation activity will help to increase the level of the latter and provide an opportunity to choose an effective strategy for innovative development. In addition, the application of the suggested analysis method makes it possible to evaluate the prospects for the development of an innovation activity within the company and creates additional motivation for the implementation of innovation projects, thereby increasing the economic sustainability of the enterprise.

Considering the interest of stakeholders in the innovation cycle contributes to timely provision for resources and growth of innovation and business activities, creation of favorable conditions for doing business, prompt decision making and implementation processes. In general, in order to stimulate innovation activity, businesses are recommended to:

- pursue policies aimed at creating opportunities for the development and marketing of innovation products. For this purpose, it is necessary to pay special attention to measures aimed at increasing the efficiency of the scientific and production foundations of the enterprise,

- increase the consumer properties of the manufactured products (this will enhance the company's competitiveness),

- provide an opportunity to improve the level of scientific and technical employees' qualifications at the enterprise,

- maximize the use of the available technological potential in combination with the funds invested in the development of new or modernization of existing products,

- develop a system of staff motivation to overcome resistance to changes related to the implementation of the innovation development strategy.

It is also recommended to evaluate the effectiveness of innovation using the indicators that may be included in the section on Corporate Governance Quality Indicators in the G4 Sustainability Reporting.

\section{Conflict of interest}

The authors have no conflicts of interest to declare.

\section{Acknowledgments}

This research has not been supported by any external funding.

\section{References}

[1] Europe 2020: A strategy for smart, sustainable and inclusive growth. URL: http://ec.europa.eu/europe2020/index_en.htm[1] Europe 2020: A strategy for smart, sustainable and inclusive growth. URL: http://ec.europa.eu/europe2020/index_en.htm (access date 17.12.2019)

[2] L. Sokolenko, T. Ostapenko, O. Kubetska, O. Portna, Thuy Tran. Cryptocurrency: Economic Essence and Features of Accounting. Academy of Accounting and Financial Studies Journal. 23(2) (2019) 16-22. URL: https://www.abacademies.org/articles/cryptocurrency-economic-essence-and-features-of-accounting8355.html

[3] B. delaHoz-Rosales; J. A. Camacho-Ballesta; I. Tamayo-Torres. Effects of innovative entrepreneurship and the information society on social progress: an international analysis, Entrepreneurship and Sustainability Issues 7(2) (2019) 782-813.https://doi.org/10.9770/jesi.2019.7.2(1)

[4] M. Klimontowicz. The role of banks' innovativeness in building sustainable market efficiency: the case of Poland, Entrepreneurship and Sustainability. 7(1) (2019) 525-539.https://doi.org/10.9770/jesi.2019.7.1(37)

[5] EuroStat. URL: http://ec.europa.eu/eurostat/statisticsexplained/ index.php/Main_Page (access date 19.12.2019)

[6] M. Pelse, D. Ziedina, L. Aleksejeva, M. Bitmane. Cooperation as a sustainable factor influencing innovation in regional development: the case of the bioeconomy in Latvia. Journal of Security and Sustainability. 7(3) (2018) 581-590.

[7] O. Lavrinenko, N. Jefimovs, J. Teivāns-Treinovskis, J. Issues in the area of secure development: trust as an innovative system's economic growth factor of bord erregions (Latvia-Lithuania-Belarus). Journal of Security and Sustainability. 6(3) (2017) 435-444.

[8] P. Atamas, M. Serbov, V. Omelyanenko, I. Kravchenko, O. Portna. Sustainable Development in the Regions on the Basis of the Stakeholder Concept. Proceedings of the 34 th International Business Information Management Association Conference, IBIMA 2019: Vision 2025: Education Excellence and Management of Innovations through Sustainable Economic Competitive Advantage. (2019) 9503-9510. URL: 
https://ibima.org/accepted-paper/sustainable-development-in-the-regions-on-the-basis-of-the-stakeholderconcept/

[9] Y. Malakhovskyi, V. Gamaliy, R. Zhovnovach, V. Kulazhenko, M. Cherednichenko. Assessment of the Risks of Entrepreneurship as a Prerequisite for the Implementation of Innovation Projects.Journal of Entrepreneurship Education. 22 (1) (2019). URL: https://www.abacademies.org/articles/assessment-of-the-risks-ofentrepreneurship-as-a-prerequisite-for-the-implementation-of-innovation-projects-7995.html

[10] N. lershova, M. Tkachenko, V. Garkusha, O. Miroshnik, L. Novak-Kaliaeva «Economic security of the enterprise: scientific and practical aspects of accounting and analytical support» // Financial and credit activities: problems of theory and practice. 2 (29) (2019) 130-141. (http://fkd.org.ua/article/view/172365/173387) DOI: https://doi.org/10.18371/fcaptp.v2i29.172365

[11] E. Witjara, S. R. Nidar, A. Herwany, S. P. Santosa The Implication of Business Partnership, Company Asset and Strategic Innovation to Business Valuation of Digital Industry in Indonesia. Academy of Strategic Management Journal. 18(1) (2019) 35-41. ). URL: https://www.abacademies.org/articles/the-implication-ofbusiness-partnership-company-asset-and-strategic-innovation-to-business-valuation-of-digital-industry-inindone-7896.html

[12] I. Perevozova, M. Savchenko, O. Shkurenko, K. Obelnytska, N. Hrechanyk. Formation of Entrepreneurship Model by Innovation Activity of Industrial Enterprises. Journal of Entrepreneurship Education. 22(1) (2019). URL: https://www.abacademies.org/articles/formation-of-entrepreneurship-model-by-innovation-activity-ofindustrial-enterprises-7997.html

[13] R. Freeman Edward, S. Dmytriyev. Corporate Social Responsibility and Stakeholder Theory: Learning From Each Other. SYMPHONYA Emerging Issues in Management, 2017.

[14] Y. Khaustova, S. Breus, S. Nevmerzhytska, T. Tsalko, T. Kharchenko. Features of Social Entrepreneurship as a Factor in the Development of Social Innovation. Journal of Entrepreneurship Education. 22 (1) (2019). URL : https://www.abacademies.org/articles/features-of-social-entrepreneurship-as-a-factor-in-the-development-ofsocial-innovation-7907.html

[15] The Global Innovation Index 2018. URL: https://www.globalinnovationindex.org/gii-2018-report (access date 02.12.2019).

[16] European Innovation Scoreboard 2018. URL: https://ec.europa.eu/docsroom/documents/30705 (access date 04.12.2019).

[17] State Statistics Service of Ukraine URL: http://www.ukrstat.gov.ua/ (access date 14.12.2019).

[18] A. Kvitka, A. Kramarenko From big business to small and medium-sized enterprises: factors and prospects. Problems and Perspectives in Management. 2 (2018) 42-48.

[19] S. Ziyadin, N. Shash, T. Levchenko, S. Khudaibergenova, G. Yessenova. Modeling of result ant effect sin assessment of innovative activity of the hotel organizations, Entrepreneurship and Sustainability. 6(4) (2019) 2180-2193.https://doi.org/10.9770/jesi.2019.6.4(43)

[20] I. Vishnich, F. Wingarten, A. Neely. Only the Brave: Product Innovation, Service Business Model Innovation, and Their Impact on Performance. Journal of Innovative Product Management. 33 (1) (2014) 526-588.

[21] M. Bondar., N. lershova., T. Chaika Strategic management accounting as an information platform for measuring innovation of the enterprise // SHS Web Conf., 67 (2019) 06006. URL: https://doi.org/10.1051/shsconf/20196706006

[22] G. Mutanov; S. Ziyadin; A. Shaikh. Graphic model for evaluating the competitiveness and eco-efficiency of eco-innovative projects. Entrepreneurship and Sustainability. 6(4) (2019) 2136-2158. https://doi.org/10.9770/jesi.2019.6.4(41)

[23] H. V. Dotsenko, I. A. Gonchar, A. I. Skrynnik, Yu. Yu. Zhebel. Stakeholder Management Tools for Enhancing Project Sustainability. Electronics and Computer Systems. 2 (2015) 150-154.

[24] V. Bondarenko, L. Martynova, N. Chorna, T. Sukhorebra, S. Seheda. Evaluation System Formation of Development of Enterprise's Innovative Potential. Academy of Strategic Management Journal. 18 (1) (2019). URL:https://www.abacademies.org/articles/evaluation-system-formation-of-development-of-enterprisesinnovative-potential-7891.html

[25] K. Slinták, P. Briš, Z. Jurigová. Innovative company: a story of Linet. Journal of Security and Sustainability. 7(3) (2018) 533-547.

[26] E. Yunus, D. Susilo, S. Riyadi, M. Indrasari, T. D. Putranto. The effectiveness marketing strategy for ridesharing transportation: intersecting social media, technology, and innovation. Entrepreneurship and Sustainability 7(2) (2019) 1424-1434.https://doi.org/10.9770/jesi.2019.7.2(44)

[27] J. Brodowska-Szewczuk. Determinants of the development of enterprises' innovativeness in the aspect of competitiveness of the economy. Entrepreneurship and Sustainability 7(2) (2019) 1279-1295. https://doi.org/10.9770/jesi.2019.7.2(33) 
[28] P. Pesti, Sucherly, N. Effendi, M. Fani Cahyandito. The Influence of Institution Partnership and Innovation Management on the Smart City Reputation. Journal of Entrepreneurship Education. 22 (3) (2019). URL : https://www.abacademies.org/articles/the-influence-of-institution-partnership-and-innovation-managementon-the-smart-city-reputation-8248.html 